\title{
As We Complete Our Second Year
}

As we complete our second year of publication, we notice how international our journal has become. We now receive submissions and publish writing from France, Italy, England, Scotland, Israel, Spain, Germany, Denmark, Finland, Hungary, Australia, and the United States. We imagine that this list will continue to grow because of the ubiquitous nature of both film and the disciplines we bring to bear on the subject of the motion picture. This internationalism is made possible by new technologies in communication, and also by the continuing internationalism of the English language. Film has been the most international of art forms since its origins and it seems only fitting that film studies should be a joint collaboration of writers from around the globe.

Although our articles stand autonomous and accessible to our readers, they also seem to pick up on and dialogue with ideas and approaches appearing in earlier issues - not so much because of any conscious plan as because of the contemporaneity of the ideas and methodologies. There is a time for all good people to come together and a place for them to find voice.

We begin this issue with Andrea Sabbadini's conversation with British film director, Mike Leigh, followed by a very articulate and telling question and answer period between the director and the audience. While film studies has been significantly involved with the psychology of the spectator, the interview is an excellent tool for exploring the psychology of the artist. By focusing on Leigh's unique improvisatory method of directing and acting, the interview also raises important issues about the psychology of acting.

We follow the interview with what we think will prove to be a significant contribution to the developing field of "neurocinematics" (the term was introduced by Uri Hasson and colleagues in the previous issue of Projections). Yadin Dudai takes the field a step further by hypothesizing on the ways in which "film uniquely fits, exploits and expands the potential of a specialized cognitive machinery in the human brain."

Eric Rabkin, one of the pioneers of science-fiction studies in the Academy, presents us with a discussion of genre by focusing on the 1931 films Dracula and Frankenstein. Rabkin's article is an elegant discussion of science fiction in film and literature that subtly brings the reader to a cognitive theory about genre. 
We have been offering translations of essays from what we consider to be a remarkable collection, Audiovisuelle Emotionen. Emotionsdarstellung und Emotionsvermittlung durch audiovisuelle Medienangebote (Köln: Herbert von Halem Verlag, 2007), itself the proceedings of a conference on audiovisual emotions in film that took place in Hamburg in 2006. Our final two essays from this collection are Jens Eder's study of Kubrick's A Clockwork Orange that develops a multileveled theory of emotion elicitation for film; and Kathrin Fahlenbrach's analysis of the ways in which sound design controls the emotional impact of image and sound on the viewer.

In all our issues we place emphasis on book reviews as part of our ongoing dialogue on film. For this issue we have asked Michael Goddard, Carl Plantinga, and Charles Eidsvik to discuss a recently published work of film theory that has drawn unusual attention.

The Editors

\section{Erratum}

The Editor regrets the misspelling of the first name of Bennett Roth for his review of Andrew Gordon's Empire of Dreams in the last issue of Projections. The corrected version of the book review is now available in the online edition of the journal. 